\title{
DA ARTE COMBINATÓRIA À ARTE INVENTIVA: PROPOSIÇÕES MATEMATIZANTES PARA UMA ABORDAGEM TÓPICO-PROBLEMÁTICA DA CIÊNCIA DO DIREITO
}

\author{
[FROM THE COMBINATORY ART TO THE INVENTIVE ART: MATHEMATIZING PROPOSITIONS FOR A \\ TOPICAL-PROBLEMATIC APPROACH OF SCIENCE OF LAW] \\ Juvêncio Almeida Costa Neto * \\ Newton de Oliveira Lima ** \\ Universidade Federal da Paraíba, Brasil
}

Resumo: O esforço de promoção do retorno ao modo de pensar tópico-problemático promovido por Theodor Viehweg, em aplicação dirigida à prática do direito, foi traduzido na compilação e publicação, em 1953, da obra Tópica e Jurisprudência. Nela, são traçados parâmetros teóricos para fundamentar o questionamento da efetividade da consideração metodológica do direito como ciência suscetível de sistematização lógicodedutiva. Viehweg sustenta, em defesa à ascensão de uma ética material dos valores, que o reposicionamento das próprias questões jurídicas concretas ao patamar mais elevado do processo de apreciação e tomada de decisões favorece a percepção de que os estatutos jurídicos abstratamente formulados merecem ocupar o status de pontos de vista socialmente aceitos - topoi -, em condições de igualdade com quaisquer outros argumentos hábeis a fornecer soluções adequadas, ante critérios temporais e espaciais, ao problema apresentado, com vistas ao desvelamento, em concreto, do sentido mais propício a preencher as lacunas correspondentes à aporia da justiça. Nesse cenário de tentativas de contraposição do pensamento lógico-dedutivo e formalista imperante, houve notável e expressa consideração, por Viehweg, dos esforços despendidos por Leibniz em buscar soluções matemáticas para os problemas jurídicos, de modo a se tornarem suscetíveis de prova e demonstração, por recurso a estratagemas
ABSTRACT: The effort to promote the return to the topic-problematic way of thinking promoted by Theodor Viehweg, in application directed to the practice of law, was translated into the compilation and publication, in 1953, of the work Topic and Jurisprudence. In it, theoretical parameters are laid down to justify the questioning of the effectiveness of the methodological consideration of law as a science susceptible of logical-deductive systematization. In defense of the rise of a material ethic of values, Viehweg argues that the repositioning of concrete legal questions at the highest level of the process of appreciation and decision-making favors the perception that abstractly formulated legal statutes deserve to occupy the status of points socially accepted topoi -, on an equal footing with any other adamant arguments to provide appropriate solutions, taking into account temporal and spatial criteria, to the problem presented, with a view to unveiling, in particular, the most appropriate way to fill the gaps corresponding to the aporia of justice. In this scenario of attempts to counteract prevailing logicaldeductive and formalist thinking, there has been a notable and expressed consideration by Viehweg of Leibniz's efforts to seek mathematical solutions to legal problems in order to become susceptible of proof and demonstration, for arithmetical stratagems, without, however, yielding irrevocably to the systematized inves- tors of law. The main

* Universidade Federal da Paraíba, Centro de Ciências Aplicadas e Educação - CCAE. ** Doutorado em Filosofia. Professor de Direito no Centro de Ciências Jurídicas da Universidade FederaldaParaiba.m@ilto: newtondelima@gmail.com 
aritméticos, sem, todavia, que cedessem, irredutivelmente, às investidas sistematizantes do direito. Este trabalho tem por objetivo essencial investigar a forma de aproveitamento da ars combinatoria na reapresentação, modernamente, da ars inveniendi aplicada à Jurisprudência. São objetivos específicos vinculados àquele alvo genérico a elucidação da forma como foi estruturada a tópica jurídica apresentada por Viehweg, em etapa preludial; $\mathrm{e}$, sucessivamente, a investigação de quais contributos - conclusivos ou refutativos podem ser extraídos a partir do entrelaçamento do pensamento aritmetizante em Leibniz e do estilo tópico de condução argumentativa apresentado por Viehweg. Dentre as principais conclusões alcançadas está a de que a experiência proposta por Leibniz oportunizou o conglobamento do estilo de pensamento por problemas com o espírito algébrico do século XVII, e, com isso, permitiu a construção de bases matematizantes pretensamente capazes de conferir suficiente segurança à apreciação casuística dos problemas jurídicos.

Palavras-chave: Ars combinatoria; Ars inveniendi; Leibniz; Viehweg; Tópica jurídica objective of this work is to investigate the use of ars combinatoria in the recent presentation of ars inveniendi applied to Jurisprudence. Specific objectives linked to that generic objective are the elucidation of the way in which the juridical topic presented by Viehweg was structured in the preludial stage; and in turn the investigation of which contributions conclusive or refutative - can be drawn from the intertwining of Arithmetizing thinking in Leibniz and the argumentative topic style of presentation presented by Viehweg. Among the main conclusions reached is that the experience proposed by Leibniz allowed the conglomeration of the style of thought by problems with the algebraic spirit of the seventeenth century, and with this, allowed the construction of mathematical bases presumably able to give sufficient security to the appreciation casuistry of legal problems.

KEYWORDS: Ars combinatoria; Ars inveniendi; Leibniz; Viehweg; Juridical topic

\section{CONSIDERAÇÕES INTRODUTÓRIAS, CONTEXTUALIZAÇÃO E APRESENTAÇÃO DO OBJETO DE PESQUISA}

$\mathrm{O}_{1}$ modo de pensar por problemas articulado por Theodor Viehweg na obra Tópica e Jurisprudência é apresentado com a pretensão de questionar, por meio do destaque conferido aos traços retóricos da justificação jurídica, a estrutura pretensamente sistemática do direito. O caráter filosófico da teoria - a qual não é considerada um "método", senão um estilo de pensamento, por prezar pela independência formal e por não ser dotada de rígidas fórmulas metodológicas de aplicação - é denotado pela abordagem crítica aos modelos dedutivos de composição lógica dos argumentos encadeados no processo de resolução de casos concretos. Para Viehweg, a tendência moderna de conferir destaque ao sistema normativo - em detrimento à questão prática a ser resolvida e às suas particularidades, no processo decisional -, por homenagem ao pensamento cartesiano e seu pretenso purismo metodológico, teria conduzido ao declínio (da) moral do/no direito. O contexto histórico de suas críticas - o período imediato à Segunda Guerra Mundial, tangente ao ápice da sobrelevação das teorias positivistas materializado por governos totalitários, no império do pensamento de matiz "neokantista" - faz ressaltar o contraste com o pensamento formalista/normativista de Kelsen, que, em via diametralmente oposta àquela percorrida por Viehweg, associa a legitimidade do direito à obediência estrita ao teor de suas prescrições imperativas - as proposições jurídicas enunciativas das normas - e condiciona sua validade à mera observância dos critérios legislativos demandados pelo próprio sistema e hierarquicamente chancelados, em primeira instância, pela 
norma constitucional e, em última esfera, pela "norma hipotética fundamental".

Em última análise, Viehweg patrocina o movimento de reincorporação, pelo direito, da autonomia para afirmação concreta da resposta mais apropriada para a aporia da justiça, por técnicas dialógicas e dirigidas à busca pelo consenso, em procedimentalização a estratégias racionais de argumentação reconhecidamente fundadas em preceitos dotados não de certeza, senão de verossimilhança e de certa medida de confiabilidade, a ser qualificada pela própria força de aceitação das inferências retóricas pelo auditório e entre os interlocutores (PERELMAN; OLBRECHTS-TYTECA, 2005, p. 96) . Com isso, cingir-se-ia o direito de necessária mutabilidade adaptativa às transmutações socialmente aceitas dos valores e da moral, conforme a respectiva disposição espacial e temporal na qual estaria o problema concreto imerso, sem, por outro lado, que fosse provocado o completo desprendimento dos lastros teóricos capazes de garantir certa segurança aos preceitos impositivos. Isso decorre do fato de que Viehweg não defende o casuísmo irrestrito ou a completa negação ao sistema: para ele, a questão é mais de subordinação entre "ordem jurídica" e "problema" - sendo sistemático o método que confere privilégio àquela primeira e tópico o raciocínio que atribui preferência a este último - que de necessária inconsistência entre ambos: é, em certa medida, intuitivo que, mesmo o raciocínio formalista reconhece que os sistemas jurídicos não consistem em fins autônomos dado que, em algum momento, terão de conferir alguma resposta prática à questão eventualmente submetida a decisão. Não por outra razão os preceitos obrigacionais derivados do sistema - mesmo aqueles representados em textos normativos abstratamente formulados - são absorvidos e conduzidos, pela teoria de Viehweg, ao patamar de respostas argumentativas - pontos de partida do discurso referidos como lugares oratórios ou topoi - passíveis de questionamento, em concreto, com vistas ao alcance conclusivo da solução mais apropriada ao caso posto.

Noutros termos: confere-se especial privilégio à discutibilidade no direito, de modo a vincular a atividade da autoridade decisora à obrigação de argumentar - em conformidade ou dissonância com as razões postas pelas partes -, ponderando-se, pragmaticamente, a pertinência de cada qual dos pleitos e justificativas. Ao final, a própria decisão alcançada poderia ser convertida em novo ponto de partida para discussões a ela supervenientes, alimentando, ciclicamente, o "sistema" - encarado como catálogo de topoi, neste caso -, mas sem a ambiciosa pretensão de relacionar previamente a inteireza das respostas universalmente válidas para todos os casos possíveis de serem posteriormente apresentados em juízo. Daí a íntima relação, inobstante a simultânea inconfundibilidade, entre a "Jurisprudência" apreciada por Viehweg - em conceito mais próximo do entendimento de "Ciência do Direito", na tradução para a língua portuguesa - e a "jurisprudência" correntemente referida, no Brasil, como entendimento prevalecente de questões jurídicas, obtido a partir do conjunto de decisões proferidas pelas Cortes: os precedentes atuam, no modo de pensar tópico, como importantes referenciais - sem qualquer vinculação definitiva, ressalte-se - potencialmente indicadores do sentido correntemente dirigido à resposta incidental de determinados problemas concretos. A reiteração decisional, por sua via, é reveladora da oportuna trilha da tendência afirmada indutivamente para problemas análogos que venham a ser postos em discussão.

Essa propensão ou predisposição - jamais certeza axiomática, porquanto inexista 
resposta satisfativa a qualquer problema que sequer fora ainda apresentado em todas as suas nuances - é limitada pela "relativa indeterminação de finalidade" decorrente da impossibilidade que acomete os legisladores humanos de "ter [...] conhecimento de todas as possíveis combinações de circunstâncias que o futuro pode trazer", conforme explicado por Herbert Hart (2007, p. 141), bem como pelo "caráter duvidoso da regularidade do comportamento humano" por nós inferido em estudo anterior dedicado à apreciação geral da estrutura de apresentação do modo de pensar por problemas proposto por Viehweg (ALMEIDA, 2012, p. 123). A abordagem problemática, aliás, motiva a própria formatação da tese tópica então defendida por Viehweg: tal qual verificado por Roesler (2002, p. 18, 19), o autor afasta a utilização de um único sistema para funcionar como plataforma de sustentação de seus construtos teóricos e recorre a "aspectos ou ideias centrais de outros autores que pudessem ser esclarecedores ou iluminadores de problemas que o preocupavam". Essa liberdade inventiva foi, em caráter quase autorreferente, essencial para o aproveitamento, a partir de teorias clássicas, de conceitos e proposições aptos a conferir soluções para seus os próprios problemas de sua empreitada, sem qualquer fidelização - ou mesmo pretensão de apego - à inteireza da base teórica de qualquer dos autores estudados.

Assim, de Giambattista Vico - a quem é feita "uma alusão", em particular, no primeiro item da obra de Viehweg - é aproveitada, sobretudo, a crítica ao manejo irrestrito do "método novo" - também nominado "crítico" ou "cartesiano" -, operado por cadeias dedutivas chamadas de sorites, para resolução de questões mais próprias de apreciação por meio do "método antigo" - igualmente referido como "tópico" ou "retórico" -, que funciona com base no manejo de alegações dotadas de verossimilhança e se destina à obtenção da resposta mais prudente no contexto de opções postas à disposição dos condutores da investigação. Mais do que a negação de um ou de outro método, cumpriria bem alcançar a melhor articulação das vantagens de ambos, conforme as demandas e características do problema eventualmente apresentado. No caso dos problemas jurídicos, a tópica retórica seria especialmente recomendável por operar uma "trama de pontos de vista" capaz de combater a "depravação do humano" e proporcionar sabedoria. Em sequência investigativa, Viehweg propõe o retorno à tópica ciceroniana e, sucessivamente, à correspondente aristotélica. Do filósofo grego, extraiu, em suma, os conceitos relacionados à dialética apresentada como "arte da discussão", reconhecendo a sua importância no processo de teorização, à época, do raciocínio por meio de pontos de vista dotados de aceitação geral; do pensador romano é colhida justamente a distinção entre os componentes da "teoria fundamental de dissertação": a "invenção" e a "formação do juízo". Para Viehweg (1979, p. 31, 32), a tópica enquanto ars inveniendi ocupou posição de destaque em três campos artísticos dos sete catalogados por Martianus Capella na obra De nuptiis Philogiae et Mercurii no quinto século d.C. e enaltecidos por Leibniz no século XVII: a gramática, a retórica e a dialética.

Com efeito, a ars combinatoria debatida por Leibniz, ainda em juventude, na sua Dissertatio foi, igualmente, objeto de apreciação por Viehweg em um relativamente curto - porém denso e eloquente - item de sua obra. Situado o contexto geral desta pesquisa, estabelece-se, como objetivo geral de investigação, o alcance da resposta ao seguinte questionamento-síntese apto a operar como problema/motriz metodológico de estudo: "em que medida o modelo de arte inventiva aplicado ao direito nos termos da 
proposição conceitual de Theodor Viehweg aproveitou - para assentir ou para refutar ou foi influenciado pela experiência da arte combinatória suscitada e desenvolvida por Gottfried Wilhelm Leibniz?". Para alcance da solução mais adequada e precisa ao problema apresentado, serão, em necessário complemento àquele alvo genérico, elencados outros objetivos - específicos - àquele principal vinculados, e substanciados no estudo: (i) em primeiro momento, do contributo legado por Leibniz à lógica por exame de sua teoria combinatória - em especial sua aplicação à jurisprudência - e da teoria do conhecimento nela embasada e desenvolvida nos anos seguintes; e, (ii) em etapa complementar, dos feixes de convergência entre as teorias tópica e matematizante ora descritas conforme abordagem proporcionada pela apreciação revisional da obra de Leibniz por Theodor Viehweg.

Para alcance do primeiro objetivo particular - a análise da arte tópica na arte combinatória -, haverá apreciação, em especial, de duas obras de Leibniz: em frente principal, conduzir-se-á estudo do capítulo 1 da obra Philosophical Papers and Letters compilado de ensaios e cartas do autor selecionadas, editadas e traduzidas por Leroy E. Loemker e publicado pela Editora da University of Chicago - com trechos selecionados do escrito Dissertatio de Arte Combinatoria, escrito em 1666; adicionalmente, será promovida análise do Livro IV da obra Novos ensaios sobre o entendimento humano Correspondência com Clarke, publicada, em 1992, pela Editora Nova Cultural (São Paulo), em abordagem mais aprofundada acerca da sua teoria do conhecimento humano. O segundo objetivo específico - investigação das repercussões da arte combinatória na arte tópica - será pretensamente resolvido pelo confronto das conclusões parciais inferidas a partir do exame particular da arte combinatória de Leibniz e, sobretudo, por aprofundamento analítico do item 6 da obra Tópica e Jurisprudência, intitulado Tópica e $<<$ Ars Combinatoria $>>$. Complementarmente, serão averiguadas as ponderações conceituais apresentadas por autores comentadores dos estudos de Viehweg.

\section{LIBERDADE CRIATIVA EM CAMINHOS ARITMÉTICOS: A ARTE COMBINATÓRIA COMO BASE PARA DESENVOLVIMENTO DE UMA TEORIA DO CONHECIMENTO EM LEIBNIZ (A ARTE TÓPICA NA ARTE COMBINATÓRIA)}

As reflexões de Leibniz acerca de uma arte combinatória ocorreram, com especial intensidade, ainda em sua juventude - em um período considerado como de relativa imaturidade científica (RUSSELL, 1968, p. 3, 5) reconhecido pelo próprio Leibniz (1992, p. 107) nos Novos Ensaios sobre o Conhecimento Humano -, e proporcionaram a publicação, em 1666, da obra Dissertatio de Arte Combinatoria. Apesar da tenra idade, o ensaio produzido - o qual consistiu em um aprimoramento do material apresentado para qualificar a disputa, ao dia sete de março daquele mesmo ano, de uma vaga na Faculdade de Filosofia de Leipzig, sua cidade natal - contém os fundamentos essenciais da estrutura do pensamento lógico-aritmético de aplicação potencialmente universal que iria nortear toda a teoria do conhecimento a ser construída, nos anos seguintes, em um "sistema complexo e coerente" de obras frequentemente dirigidas a interlocutores com quem desenvolvia debates ou a quem conferia respostas a questionamentos filosóficos. O projeto artístico-filosófico de Leibniz (2011, p. 117) consistiu em formular um expediente destinado a orientar a 
extração, por meio de combinações e permutações, de conceitos complexos a partir de preceitos simples - de modo a, com isso, derivar teoremas básicos e úteis à solução de problemas concretos em lógica, jurisprudência, teologia e diversos outros campos do conhecimento. Dentre as três seções introdutórias designadoras das fundações lógicas da empreitada teórica de Leibniz se encontram (i) a demonstração da existência de Deus; (ii) a preparação dos corolários da obra; e (iii) as definições relativas ao trabalho em si.

Especificamente no que concerne ao esforço conceitual na técnica combinatória de Leibniz (2011, p. 84, 126), três itens deveriam, conforme o autor, ser considerados: os problemas, os teoremas e as aplicações. Ao apresentar o problema da descoberta da quantidade de "complexidades" - conversão de um conjunto menor de itens em outro de maior dimensão, em ideia aproximada ao conceito corrente de "combinações simples" - de um número e de seu expoente, por exemplo, Leibniz observou a possibilidade de resolução da questão de duas formas: uma aplicável de modo genérico, por tentativas intercaladas, e outra funcionalizada em combinações sucessivas. Enquanto aquela primeira estratégia seria dotada de amplitude prática relativamente maior, esta última demandaria menos informações para ser operacionalizada. Além disso, a técnica combinatória dispensaria a pressuposição de que as complexidades antecedentes já tenham sido desveladas, ao contrário daquele outro modelo - o que a tornaria, em certa medida, mais eficiente. Ao discorrer acerca da aplicabilidade do método combinatório, Leibniz (2011, p. 130) argumenta que todas as coisas existentes ou que podem ser concebidas - ainda que imaginativamente - são compostas por partes, as quais podem ser, em mesma medida, reais ou conceituais.

Desse modo, tudo quanto difira em "tipo" deve necessariamente divergir quanto às demais secções de que seja constituído ou mesmo quanto ao posicionamento das porções eventualmente comuns. A primeira distinção - motivada por variações materiais - provoca o resultado díspar das complexidades alcançadas; e a segunda - por oscilações de forma - conduz ao uso igualmente particularizado das disposições desvendadas. Com o auxílio das combinações, tornar-se-ia possível não apenas desvendar novas espécies de coisas, como, também, compreender seus respectivos atributos - razão por que, para Leibniz, quase toda a parte inventiva da lógica está fundada em complexidades: tanto os tratados sobre divisões, quanto aqueles dedicados às proposições, bem como a parte analítica da lógica e a lógica decisional per se. Sucessivamente, aliás, à descoberta de novas espécies de coisas afeitas à especialidade do conhecimento estudada, poderiam ser desvelados gêneros comuns àquelas espécies e as espécies derivadas de divisões deles distintas -, e, em fase conclusiva, também os gêneros subalternos. Em medicina, exemplifica Leibniz (2011, p. 130-133), toda variedade de componente medicamentoso ou farmacêutico é obtida a partir da mistura de ingredientes diversos - partes da combinação simples de itens postos à disposição conforme as funcionalidades dos compostos e a respectiva necessidade de que seus princípios ativos operem em maior ou menor concentração.

No que concerne ao direito, por sua via, a formação de casos encontraria similar correspondência na doutrina combinatória - sobretudo nas situações em que se almeje compor a combinação do rol de leis aplicáveis a uma questão concreta, com vistas a evitar legar ao acaso a corretude de determinada conduta ou problema concreto. Leibniz compara com eloquência, aliás, a estruturação da Ciência do Direito à da geometria: (i) 
ambas seriam compostas por elementos e problemas; (ii) os elementos apresentar-seiam com singeleza nos dois contextos - em geometria há figuras, triângulos e círculos, enquanto em direito há ações, decisões e leis -, e os problemas - ou casos concretos figurariam com complexidade variável nos dois casos; (iii) em geometria, haveria estabelecimento paradigmático dos "Elementos Euclidianos" e, em direito, o Corpus Juris operaria com análoga função referencial à sua época; (iv) e, finaliza, em ambos os campos "more complicated cases are added" - casos mais complicados são acrescidos -, em linha argumentativa que levanta, de pronto, a própria percepção da necessidade do aprimoramento inventivo/criativo nos dois contextos. Desse modo, coleções de topoi como aquelas sistematizadas por Bernhard Lavintheta nos comentários da Ars Magna de Raimundo Lúlio poderiam operar como pontos de partida de que disporia o interessado para, mediante combinações sucessivas, trilhar, em níveis decrescentes de generalidade, o caminho para as respostas mais adequadas ao problema proposto.

O esforço inventivo implantado em um método pretensamente objetivo de apreciação de problemas concretos é derivado da premissa de que parte Leibniz (2011, p. 120) consistente na aferição de que a lógica não é um fim em si mesmo - e de que ela tampouco se dirige ao silogismo, senão à contemplação: a proposição lógica seria ferramenta direcionada a essa finalidade, e o silogismo operaria como mero meio para a visualização coordenada daquelas proposições. Adicionalmente, explica que, embora qualquer método possa ser aplicado a qualquer disciplina, não é conveniente fazê-lo de forma indiscriminada - motivo pelo qual adaptações seriam sempre demandadas, em maior ou menor grau, ainda que mantida a essência da técnica comum manejada. Quanto a essa questão, Loemker ressalva, em comentários à obra de Leibniz (2011, p. 84), que a matemática em seu período se referia a uma consideração abstrata de relações metafísicas, as quais fundaram, com frequência, a abordagem da lógica nos escritos do autor alemão. Em Novos Ensaios sobre o Entendimento Humano, escrito datado de 1704 no qual emula um diálogo fictício entre duas personagens - Teófilo e Filaleto -, Leibniz (1992, p. 83) rememora o valor da invenção tanto para explicação de um "tema incomplexo" - uma coisa ou uma ideia -, quanto para "a prova de um tema complexo" - "uma tese, proposição ou verdade".

Nesta etapa já aprofundada e amadurecida de seus estudos filosóficos, Leibniz (1992, p. 88-99) concebe a gradação do conhecimento humano em quatro níveis: o da intuição, o da demonstração, o da sensibilidade e o da probabilidade. Naquele primeiro estariam inseridas as ideias percebidas e concordadas imediatamente pelo espírito "em virtude delas mesmas, sem intervenção de outras"; o conhecimento demonstrativo, por sua via, consistiria na disposição encadeada de conhecimentos intuitivos nas conexões das ideias mediatas; sensível corresponderia à percepção respeitante à "existência particular dos seres finitos fora de nós"; e, por fim, probabilístico seria o conhecimento fundado em opiniões verossímeis. Leibniz dedica especial atenção à modalidade demonstrativa do conhecimento e explica que consiste em sequência de ideias mais complexa e, em certa medida, menos clara que as conclusões derivadas da intuição. $\mathrm{O}$ fato de lidar com insumos lógicos pretensamente verídicos e presumidamente verificáveis quanto à sua corretude - porquanto vinculadas, particularmente, ao conhecimento intuitivo - não afastou a percepção de existência de invenção, em Leibniz: o filósofo trata como problemáticas as "questões que deixam uma parte da proposição em branco", dentro do esforço de análise, e pondera que graus de invenção 
podem ser identificados conforme a (in)existência de questões a resolver entre o sujeito e o predicado.

Com efeito, Leibniz (1992, p. 93, 94) argumenta que, nos tempos em que os métodos analíticos não haviam sido ainda sistematizados, era exigida maior sagacidade - "espírito de vontade para alcançar provas" - para encontrar a demonstração de questões por meio de técnicas que demandavam do estudioso maior grau de criatividade e invenção. Isso teria ocorrido, avalia, mesmo entre os matemáticos, porque haveria maior dificuldade em desvelar verdades relevantes - criar - que em encontrar formas para demonstrar conclusões descobertas por outros - demonstrar com base em intuições. Não por outro motivo incumbiria aos algébricos e geômetras designar as "verdades intermediárias" - o que também traduziria esforço tópico - de modos que auxiliassem a memória e a compreensão do raciocínio, uma vez que deduzir a inteireza das demonstrações implicaria em uma "prolixidade insuportável". O fato de Leibniz abordar a importância da criação no desenvolvimento de raciocínios demonstrativos, em primeiro momento, para, apenas subsequentemente, conceber o campo dos juízos probabilísticos - dentro do qual, em tese, a tópica estaria melhor inserida, para Viehweg -, acrescido da constatação de, mesmo no âmbito daquela primeira espécie, abordar questões afeitas à invenção e à tópica permite inferir com segurança que seu posicionamento acerca da aplicabilidade da ars inveniendi não estaria adstrito ao mero campo dos lugares comuns, encarados como pontos de vista de aplicabilidade genérica e socialmente aceitos.

Este, a propósito, é um dos pressupostos de que parte Viehweg $(1979$, p. 71) para apreciar as contribuições legadas por Leibniz para a matematização do raciocínio tópico: a teoria combinatória se declina ao posicionamento de que a jurisprudência pode ser convolada ou apreciada como se método fosse - o que conduz às tentativas de matematizá-la -, mas, concomitantemente, questiona a eficiência do raciocínio lógicodedutivo, isoladamente, para alcance da razão. Em conferência apresentada no âmbito do Colóquio Leibniz no Nordeste - realizado na Universidade Federal da Paraíba, em novembro de 2017 - e intitulada Leibniz et Le meilleur des mondes possibles, Paul Rateau (2017, p. 18-27) esclarece que, para Leibniz, conjecturas, presunções ou probabilidades não seriam dotadas do mesmo valor demonstrativo que um raciocínio apodítico - por ser este último "derivado de razões a priori" e, consequentemente, por ter, em filosofia, "um peso superior a tudo que vem de considerações somente a posteriori" -, mas o manejo dessa categoria insuscetível de demonstração estrita não implicaria, necessariamente, em "falta de rigor ou cientificidade", caso o contexto de destinação justifique seu uso. Leibniz $(1992$, p. 96, 97, 178, 187) pondera que o silogismo se serve, em essência, ao apontamento da conexão das provas já existentes em um exemplo e tece críticas a Aristóteles: em uma frente, sustenta que, apesar de os silogismos consistirem em "uma espécie de matemática universal, cuja importância não é suficientemente conhecida", os sistemas das formas da argumentação propostos pelo estagirita "não constituem o único nem sequer o melhor instrumento para raciocinar"; em abordagem complementar, defende que o conceito de "opinável" não pode equivaler, restritivamente, à ideia de topos, sob pena de legar ao raciocínio por pontos de vista uma mera argumentação mediante provérbios ou "regras populares" destinadas a "amplificar o discurso e conferir-lhe boa aparência".

Pela máscara da personagem de Filaleto, Leibniz (1992, p. 188) sugere que, se a 
inferência dedutiva é a conclusão como verídica de uma premissa por estar ela conectada a outra aprioristicamente enquadrada como verdadeira, caso sejam dirigidos esforços para "distinguir as ideias das quais depende a consequência daquelas que são supérfluas", de modo a organizá-las em uma "ordem natural", a incoerência poderia ser igualmente identificada, tornando prescindível a movimentação de inúmeras sentenças lógicas para alcance da mesma finalidade. Em aprofundamento das contraposições teóricas, menciona, ainda, a amplitude do desconhecimento, no âmbito das pessoas em geral, do conceito de silogismos e a existência, mesmo assim, daqueles que identificam com facilidade as fragilidades de um "longo discurso artificioso e plausível". Em arremate, recorda que "raramente o método do silogismo chega a convencer pessoas", limitando-se os interlocutores, no máximo, ao reconhecimento do preparo técnico do adversário, e, com razoabilidade, à inferência de que "se se podem envolver raciocínios falaciosos em silogismos, é necessário que a falácia possa ser descoberta por um outro meio que não seja o silogismo". Ao iniciar a resposta pela personagem de Teófilo - a qual se aproxima mais de seus posicionamentos filosóficos -, entretanto, Leibniz (1992, p. 189) confere valor ao desenvolvimento do silogismo - qualificando-o como "uma das mais belas [invenções] do espírito humano" e contra-argumenta que ele é capaz de encerrar uma "arte de infalibilidade", desde que haja suficiente domínio de seu modo de operação. Apesar disso, cede à constatação de que "existem consequências assilogísticas boas", insusceptíveis de demonstração por raciocínio lógico-dedutivo.

No que concerne à segunda crítica à teoria aristotélica dos Tópicos, Leibniz (1992, p. 178) pondera, acertadamente, que a probabilidade deveria ter sido objeto de estudo destinado a mensurar seus graus de ocorrência e que ela pode até convergir com a opinião geral de agentes expertos, mas jamais a esse critério restringir-se-ia: seria preciso deduzi-la especificamente da natureza das coisas e de todas as suas manifestações, de modo que figuraria igualmente possível extrair a verossimilhança das inferências por outros esforços. Em seguida, como exemplo, suscita o caso de Copérnico, no qual o mais elevado grau de probabilidade teórica por si defendida se mostrou isolado, em contraposição à opinião geral manifestada pelo paradigma científico vigente - em representação metonímia à própria percepção social geral. Nesse ponto, todavia, a indistinção material dos espaços de manejo dos raciocínios demonstrativo e probabilístico de que lançou mão Leibniz pode ter contra si revertido efeitos: a tese poderia ser questionada, por Viehweg, no sentido de que a referida situação concreta por Leibniz aventada não acobertaria campo, por excelência, do raciocínio por pontos de vista, dada a oportunidade de demonstração fenomenológica daqueles resultados de pesquisa por métodos lógicos e fundados em intuições, nos termos do próprio Leibniz. Noutros termos: a invenção poderia ser ferramenta eficaz para suscitação do problema concreto, mas nada impediria a submissão de suas referências ao raciocínio demonstrativo. Vista dessa forma a articulação da tópica no manejo do raciocínio combinatório, aspectos positivos poderiam ser extraídos e, com a apreciação artística da probabilidade, o problema levantado por Leibniz não subsistiria caso demonstrada a insustentabilidade da tese por argumentos apodíticos - derivados de razões a priori.

Em verdade, na mesma medida em que Viehweg (1979, p. 18) concebe a tópica como teoria da prática argumentativa, Leibniz $(1992$, p. 135, 170,171, 177) reconhece que a privação de estímulos à conciliação de saberes práticos no contexto de 
apreciações morais - especialmente nas escolas de filosofia, mas em raciocínio igualmente servível à Jurisprudência -, conduz à carência de conclusões bem sucedidas e de respostas eficientes aos problemas concretos levantados. Os próprios julgamentos advindos do alcance de um "crepúsculo de probabilidade" se mostrariam adequados apenas quando fundados na percepção acertada da realidade das coisas materializada em provas argumentativas. Daí a faceta simultaneamente tópica e lógica da praxis jurídica: a partir de um fato concreto e de todos os sistemas jurídicos capazes de responder um problema relacionado àquele acontecimento, ordens estruturais do raciocínio poderiam ser operacionalizadas, sem que seja minado o caráter inventivo da convocação de elementos de cada uma dessas estruturas. Ou seja, a partir de uma inferência singular - fática ou normativa -, haveria a extração sucessiva de tantas outras quantas fossem necessárias para a comprovação da tese que se quer hastear combinação simples, portanto. Leibniz (1992, p. 94-96) sugere a ordem de apreciação reputada aos "jurisconsultos", com base ordenada, em ordem decrescente de força: (i) nos fatos notórios - os quais dispensam a produção probatória; (ii) nas "provas inteiras" - acerca das quais é levantado certo pronunciamento; (iii) em havendo necessidade, nas próprias "provas mais do que plenas" - a exemplo do exame de corpo de delito; (iv) nas "provas plenas comuns"; (v) nas presunções relativas - tidas provisoriamente como provas inteiras, até a demonstração do contrário; (vi) nas provas mais e menos do que "semiplenas"; bem como, enfim (vi), nas conjecturas e (vii) nos indícios.

Por conseguinte, apesar de as verdades fáticas serem suscetíveis de provas - não necessariamente de demonstrações a priori, porque "suas análises nunca são concluídas, mas continuam até o infinito" -, Leibniz (1992, p. 94) refuta expressamente a alegação de que apenas as ciências matemáticas têm a aptidão de conferir inferências demonstrativas mediante concordância ou discordância de premissas fornecidas por intuição. O campo da jurisprudência seria, fora daquele saber numérico, um dos mais propensos à apresentação de demonstrações porquanto seja afeito à lógica, a qual se mostraria "tão suscetível de demonstrações como a geometria". Rateau (2017, p. 27) desenvolve a ideia ao elucidar que quanto mais próximas da forma lógica, maior o grau de probabilidade deduzido a partir do encadeamento argumentativo formulado, dado que as relativas imprecisões de conteúdo seriam suplantadas pela segurança aduzida a partir dos vínculos de verdade entre as proposições selecionadas.

Vivianne de Castilho Moreira (2017), harmonicamente, ilustra a questão ao propor a solução imagética de polígonos sucessivamente intercalados, dentro de um círculo, de modo que todos os seus vértices tangenciem um dos pontos da circunferência limitadora e o ponto central da aresta de cada um dos polígonos exteriores consista no vértice do polígono interior imediato: independentemente da quantidade de novas figuras que venham a ser desenhadas para preenchimento dos loci vazios entre os polígonos e o contorno circunferencial, jamais haverá pleno alcance, idealmente, da total coincidência dos pontos da circunferência com aqueles correspondentes às arestas do maior polígono existente na área do círculo. Paralelamente, inobstante o apego à forma, jamais se alcançaria, por emprego de argumentos verossímeis - porquanto prováveis -, a certeza típica das inferências derivadas de preceitos aprioristicamente intuídos ou percebidos ab initio. O esforço argumentativo, entretanto, corresponderia aos níveis poligonais cada vez mais próximos do círculo externo: apesar da impossibilidade de pleno tangenciamento, as figuras 
internas reduzem a existência de espaços vagos entre si e o círculo central a cada nova unidade poligonal concebida, fazendo os seguimentos de reta se aproximarem cada vez mais do ideal circular. Entre o ponto de origem e o limite externo, podem ser extraídas infinitas derivações, mas nenhuma delas corresponderá, terminantemente, ao próprio ideal formalmente almejado. Nos termos de Viehweg (1979, p. 38), apesar das eventuais soluções incidentes, o caráter problemático da questão posta será permanentemente mantido, dada a infinidade de respostas aplicáveis. Daí a compreensão de que a empresa de Leibniz consistiu em conglobar as "forças humanas" de criação e racionalização na fórmula prática de "invenção" encarada como ars (BONNEAU, 2015, p. 205).

Em termos de conclusão parcial de estudo, é possível inferir que o esforço de Leibniz quanto ao desenvolvimento da arte combinatória aplicada - ou aplicável - à Ciência do Direito foi dirigido à manutenção da suposta - e relativa - previsibilidade funcional dos resultados do procedimento dedutivo obtido a partir do manejo de raciocínios silogísticos, sem que isso viesse a minar a liberdade criativa do agente no processo de resolução do problema, por meio do apontamento desimpedido de premissas inventadas conforme as demandas do próprio caso apresentado. Importa considerar que o amadurecimento de Leibniz e o aprofundamento de seus estudos repercutiram nos posicionamentos sustentados nas obras estudadas, durante as duas fases da sua vida nas quais foram respectivamente escritas. Embora não tenham sido constatadas - no específico campo material investigado - incongruências que inviabilizem a concorrência sistêmica dos escritos, é possível denotar que, enquanto a arte combinatória dos momentos iniciais de sua trilha filosófica se mostra mais preocupada com a resolução prática de problemas concretos - em aplicações amplas que trespassariam a mera fronteira limitadora do conhecimento numérico -, a teoria do conhecimento formulada anos mais tarde reúne, com especial densidade, um arcabouço conceitual particularizado - eminentemente inclinado ao reconhecimento de estruturas básicas de demonstração -, dirigido ao estabelecimento de critérios para o exercício da atividade de achamento de proposições e inferências lógicas e, sucessivamente, ao atestamento de sua validade.

$\mathrm{O}$ escrito sobre arte combinatória estabelece os fundamentos para $\mathrm{o}$ desenvolvimento de uma teoria do conhecimento que busca - de modo ambicioso conglobar as vantagens da concomitância de opostos metodológicos - a tópica e o silogismo -, com vistas a extrair de ambos o melhor aproveitamento no processo de classificação das coisas e de formulação de soluções para questões tangíveis. Seu funcionamento - ao menos no campo jurídico - seria dado pela combinação de premissas derivadas a partir de pressupostos elementares - de ordem preferencialmente fática, referentes ao caso concreto e acompanhadas de todos os relatos e provas postos à disposição - articuladas a outras premissas extraídas de sistemas jurídicos - os topoi enquanto insumos sistêmicos - que se amoldem, de forma adequada, às exigências e necessidades decorrentes daquele problema posto em discussão. As discussões seriam fundadas em catálogos de pontos de vista - tal qual aquele enunciado por Raimundo Lúlio, em sua Ars Magna - e os argumentos utilizados deveriam ser lógicos e dotados de verossimilhança, estando o seu principal diferencial na possibilidade de sugestão criativa de hipóteses solucionadoras para alimentação do esforço renovador corporificado na arte inventiva. Ao final seria alcançada "demonstração" - ou 
comprovação - mais próxima do grau de certeza almejado - ainda que jamais inteiramente conclusiva, razão por que seu caráter problemático é mantido mesmo no estágio resolutivo, em relativa convergência com as premissas do pensamento tópico de Viehweg.

A partir da fixação dos resultados de pesquisa enunciados, o próximo item desta pesquisa declinar-se-á ao aprofundamento das linhas interseccionais entre as conclusões preliminares indicadas e as bases de inspiração para o desenvolvimento, modernamente, do ensaio ao retorno ao modelo tópico-problemático como referencial de resolução de problemas jurídicos, por Viehweg.

\section{PRETENSÕes MATEMÁtiCAS PARA EMPREENDIMENTOS INVENTIVOS: AS POSSÍVEIS CONVERGÊNCIAS ARTÍSTICAS ENTRE "MÉTODO" E "TÓPICA" NA TEORIA DO PENSAMENTO POR PROBLEMAS DE VIEHWEG (A ARTE COMBINATÓRIA NA ARTE TÓPICA)}

Para Viehweg $(1979$, p. 33, 34, 71), os problemas que motivam o modo de pensamento tópico são definidos como questões que demandam certo conhecimento prévio, que aparentemente admitem mais de uma solução como possível e que exigem o apontamento de uma resposta, incidentalmente, a qual deverá ser extraída de um sistema previamente posto mediante "um conjunto de deduções". O caráter problemático do estilo inventivo encontra distinção no foco que é conferido a essas questões, em relação aos métodos sistêmicos - ou lógico-dedutivos - e encerram "aquilo em torno do que os raciocínios giram", com assumida inspiração na teoria aristotélica sobre a matéria. A ars inveniendi eleva, desse modo, o problema concreto ao patamar de "guia" para resolução da eventual aporia posta - o que não ocorreria no "pensamento sistemático" - e, em função disso, conservaria seu posto de "estilo", jamais podendo ser convertida em método, "pois só pode chamar-se método um procedimento que seja lógica e rigorosamente verificável e crie um nexo unívoco de fundamentos". Viehweg não esconde sua intenção em manter a tópica longe de demonstrações rigorosas, preferindo, em uma autocrítica desembaraçada, o que ele próprio nomina de "arbítrio amorfo". A confiabilidade do modo de pensar por problemas decorreria de aptidão, prática e certa "atitude espiritual" dirigida ao seu exercício, por seu praticante, mas nada disso faria a tópica jurídica ser enquadrada como ferramenta suscetível daquilo que Leibniz encarou como raciocínio demonstrativo.

Tal qual exposto no item antecedente desta pesquisa, entretanto, Leibniz, sem afastar a influência criativa das práticas inventivas da argumentação, concebeu a aplicação demonstrativa lato sensu no âmbito da Jurisprudência - mediante a estrutura mais "leve" e menos estrita de "comprovação" - ao formular sua teoria combinatória, e ratificou seu posicionamento em momento, posterior - estágio de maior maturidade intelectual -, ao apresentar sua teoria do conhecimento na obra Novos Ensaios sobre o Entendimento Humano. Essa proposição formal foi apreciada por Viehweg, que dedicou um dos parágrafos da obra Tópica e Jurisprudência ao estudo dos possíveis enlaces entre o modo de pensar por si proposto e a arte combinatória patrocinada por Leibniz. Já ao início de sua investigação, o filósofo do direito esclarece os pontos nefrálgicos de divergência entre ambas as proposições teóricas e esclarece que Leibniz 
partia de premissas distintas das suas, especialmente quanto à possibilidade concreta de "fazer concordar o tradicional estilo de pensamento da Idade Média com o espírito matemático do século XVII", em referência respectiva à tópica e à combinatória - a qual não conseguia encarar como procedente.

Viehweg (1979, p. 72) entende que o principal mérito de Leibniz foi ter afastado um modo estritamente sistemático-dedutivo em sua teoria combinatória destinada ao alcance de provas do que se alega: apesar de não fazer, nominalmente, referência expressa à tópica jurídica, teria reconhecido "que a herdada ars inveniendi [...] pode ser colocada sob controle aritmético". Isso ocorreria sem que haja absoluta supressão de sua estrutura fundamental de combinações e, a partir daí - com a conversão da arte inventiva em arte combinatória -, se extrai a pretensão de tornar aritmeticamente verificável o pensamento tópico. Intentou Leibniz por construir uma doutrina fundada em complexidades e transposições - e estruturada em fórmulas - para "dar novos estímulos à arte de meditar ou arte da invenção lógica". Roesler (2002, p. 185) interpreta que o racionalismo de Leibniz é traduzido no interesse de formalizar os métodos de raciocínio e de retratar o saber humano mediante a formulação de uma "notação adequada para a representação de todo o nosso conhecimento", bem como de um "cálculo rigoroso para manipular adequadamente estas representações", com vistas a que todos os problemas concretos pudessem ser apresentados e resolvidos por cálculos - o que, por via sucessiva, habilitaria a fácil detecção de impropriedades materiais por inconsistência formal com a notação matemática e posterior correção "como simples erros de cálculo".

A inspiração mecanizadora para a arte combinatória teria advindo dos círculos giratórios e concêntricos apresentados por Raimundo Lúlio - na obra Ars Brevis, de 1308. Em cada um daqueles círculos haveria cinco qualificadores genéricos e outros conceitos específicos a eles respectivamente relacionados, formando uma espécie de "árvore combinatória" (FRAZON; BRITO, 2013, p. 2, 3). Lúlio nominou a estrutura como Ars Magna e, com ela, intentava, originalmente, criar uma ciência de matiz matemática universalmente aplicável, destinada a, por intermédio de raciocínios articulados, coerentes e ordenados logicamente, converter pessoas à fé cristã. A tese enunciada era posta - em pretensa demonstração - por meios alegadamente racionais seccionados, em início, em termos simples, e, conforme o avanço da exposição, encadeados, sucessivamente, em combinações múltiplas e articuladas de complexidade crescente. Apesar de Leibniz ter compreendido a validade da representação geométrica das combinações conceituais, a escolha dos itens enunciados por Lúlio teve sua discordância: o autor alega que houve excessivo arbítrio na eleição dos conceitos, bem como que foi promovida, de um lado, a supressão indevida de itens que deveriam estar presentes, e, de outro, a inclusão de noções que não se mostraram pertinentes (CHARLES, 2014, p. 194).

A aplicação dessa estrutura combinatória no direito - mantendo-se a ideia central de cálculo -, todavia, seria possível, mediante ajustes, e ocorreria por meio da transposição de "fórmulas iniciais" a outras "posições", em alinhamento a preceitos operativos fixos e simples. Esse encadeamento lógico conduziria a relações algébricas: as "proposições fundamentais" estariam para as "fórmulas iniciais", como os "conceitos" estariam para as "variáveis nessas fórmulas" e as conclusões, para os "preceitos operativos da combinatória". Ao final, seriam ainda introduzidos "alguns 
sinais simbólicos parecidos com os da matemática". Para Viehweg (1979, p. 73, 79, 80), a empresa casuística de Leibniz dirigida à algebrização da tópica aplicada ao direito por meio da conversão da relação do todo adjacente ao pensamento com seu centro não logrou êxito. Isso teria ocorrido, segundo comenta, em virtude da "multivocidade da linguagem natural" - o que teria levado o próprio Leibniz a tentar criar, posteriormente, uma linguagem pretensamente unívoca - também sem sucesso. Viehweg explica que Leibniz teria desviado o foco de sua empreitada para a questão linguística porque "na linguagem natural, um sistema dedutivo não é suficientemente seguro contra as influências da tópica".

Viehweg $(1979$, p. 79, 80) argumenta que, de um lado, as proposições matemáticas de Leibniz não eram dotadas de direcionamento disciplinar aplicacional por trabalharem com "signos que na realidade não significam nada". Além disso, de outro lado, o seu contexto de emprego necessitaria de referência especial ao mundo concreto, o qual, por sua vez, faz dotar o cálculo de um preceito interpretativo que, "do ponto de vista lógico, é arbitrário". A partir daí, o retorno à tópica, na prática, seria inevitável na mesma medida em que indesejável para os "formalistas puros": alega Viehweg que "a tópica nunca pode ser totalmente eliminada no começo de um sistema real - entre nós, de um sistema jurídico - [porque ela] reaparece no preceito de interpretação, que é indispensável para que um cálculo - aqui, um cálculo jurídico seja aplicado". Não haveria triunfo, portanto, em almejar a concretização de encadeamentos argumentativos válidos fundados em cálculos estruturados em fórmulas lógicas previamente postas e em símbolos de uma linguagem inequívoca, sem qualquer pretensão de apego ao significado do que esteja posto (FRAZON; BRITO, 2013, p. 6).

Apesar do alegado malogro da ars combinatoria, compreende-se que os esforços de Leibniz contribuíram substancialmente para que a teoria de Viehweg ganhasse força simbólica: para o autor responsável pelo reacendimento moderno da tópica, o revés da arte combinatória foi indicativo concreto de que a formalização - mesmo aquela apresentada sem completo abandono do problema como questão motivadora de toda a estrutura decisional - é dotada de limites intransponíveis e qualquer tentativa de uniformização linguística dela decorrente seria contida pela resistência social de aceitação e pela inconveniência prática (ROESLER, 2002, p. 185). Viehweg encara como vitoriosa, portanto, a comprovação da dissonância entre as premissas apontadas ao início da sua análise da teoria combinatória, em relação ao seu estilo de pensamento e a teoria de Leibniz - representadas, in casu, pela discordância daquilo que considera como ingênua crença, por parte de Leibniz, ainda em sua imaturidade intelectual, de que haveria possibilidade de articular o modo de pensar tópico ao pensamento matemático imperante em seu período.

O próprio posicionamento da análise da obra de Leibniz em seu texto é indicativo de que lhe era conveniente tratar da arte combinatória apenas após a consolidação das teses e argumentos que lhe eram favoráveis quanto à tópica - com estribo na articulação assistemática do pensamento isolado de autores como Aristóteles, Cícero, Vico e Hartmann -, em essência para poder refutar, com o acúmulo da força retórica do que já apresentara anteriormente, os aspectos lógicos da estrutura da teoria matematizante: na edição original, o parágrafo dedicado à composição comparativa entre tópica e arte combinatória apenas antecede o item que trata da relação entre o modo de pensar por problemas e a axiomática - relacionado àquele anterior, por fazer 
referências esparsas à combinatória - e o capítulo sobre as conexões entre a tópica e a civilística, que tem finalidade fundamentalmente exemplificativa do emprego do modo de pensar por problemas em um sistema jurídico concreto.

Apesar da recepção arisca por Viehweg, o contributo de Leibniz à tópica não é, de todo, desprezível - nem deve ser limitado à mera confirmação da tese de impossibilidade de consideração da Ciência do Direito como método: como apresentado no item antecedente deste estudo, Leibniz conforma, em sua teoria amadurecida sobre o conhecimento humano - a qual cumpre analisar em articulação aos seus estudos sobre a arte combinatória -, as necessárias divergências entre as demonstrações apriorísticas e aquelas insuscetíveis de provas por si mesmas. Se as primeiras são dotadas de certeza, não se haveria negar importância às conclusões das segundas, caso sejam dotadas de proximidade da forma lógica capaz de assegurar-lhes suficiente grau de probabilidade. Há reconhecimento expresso, por Leibniz, das limitações da lógica dedutiva, mas, em mesma medida, evidencia-se a relevância de aproveitamento da segurança e força decorrentes da obtenção de respostas a partir do encadeamento de asserções em uma fórmula lógica previamente estabelecida.

Sua intenção em conferir à tópica traços matematizantes se coaduna com o intento legítimo de estabelecer formas estáveis de resolver problemas com base em premissas dotadas de verossimilhança. Além disso, a racionalização de seu discurso consubstanciada justamente na relativa margem de manutenção da criatividade e da invenção, aliada ao esforço de garantir caráter prático à moral - não é mitigada ou, tão menos, suprimida pela proposição formal de matiz combinatória: todas as inferências obtidas com base em combinações são comunicadas a preceitos simbólicos dotados de certa abertura semântica e amplitude conceitual, em esforço de pensamento que, atualmente, se aproxima daquele manejado no contexto de interpretação tópica de princípios constitucionais - constantemente festejado. Se, como defendido por Viehweg, a interpretação é o ponto inevitável de ocorrência da tópica no discurso jurídico, é igualmente verídica a constatação de que o modo de pensar por problemas não é pragmaticamente aplicável sem a presença de sistemas bem definidos de normas jurídicas - ainda que sejam elas apresentadas em maior grau de abstração, e tão melhor quanto mais vagos, abertos, porosos e amplos em diversidades enunciativas sejam os preceitos considerados.

Por conseguinte, o esforço de concretização racional desses preceitos - aberto à margem criativa inevitável às combinações aduzíveis -, tal qual proposto por Leibniz é de ser tido como plenamente conciliável a uma proposta pragmática de tópica jurídica: de um lado, permite o estabelecimento dos catálogos de tópicos que poderiam ser manejados, com vistas a garantir certa estabilidade ao jogo de articulações de pontos de partida; e, de outro, oferece oportunidades dialógicas variáveis a todas as partes interessadas conforme as combinações adotadas por elas - para a defesa dos respectivos pontos de vista. Mesmo o decisor, observado o dever de fundamentação argumentada do posicionamento adotado, manejaria as combinações possíveis - e indicaria aquela apresentada como a melhor dentre as possíveis -, com vistas ao alcance, em caráter conclusivo - ainda que não terminativo, porquanto sujeito a referências para assentir ou para questionar, quer no âmbito do mesmo processo, quer no âmbito de outros feitos da solução por si enunciada.

Com efeito, em singela avaliação da questão aplicada à prática jurídica corrente 
no Brasil, a diversidade de sistemas jurídicos dentro do próprio ordenamento permite que sejam extraídos preceitos alinhados com a teoria combinatória de Leibniz: os sistemas legais stricto sensu mantém certa independência em relação ao das normas constitucionais - a eles subordinados -, assim como ao de Súmulas de Tribunais, bem como ao de precedentes dessas Cortes, e ao do posicionamento doutrinário prevalecente - a título exemplificativo. Ainda que haja consenso quanto à distribuição hierárquica e a existência de certa comunicação entre todos os sistemas enunciados, há, em certa medida, liberdade de referência a todos eles - de modo inventivo - para alcance do convencimento decisional. Não sendo razoável conceber o manejo de uma estratégia de resolução de questões jurídicas carente de referenciais normativos e exclusivamente fundada em aporias - como se extrai de leitura fria do contributo originário de Viehweg -, a saída proposta por Leibniz, com as necessárias adaptações, não apenas pode funcionar como método comunicativo de premissas - normativas e fáticas - capaz de articular soluções concretamente direcionadas sem se ater irrestritamente às arbitrariedades sistêmicas: em muitos aspectos já o faz.

\section{CONSIDERAÇÕES CONCLUSIVAS}

Esta pesquisa foi motivada pelo questionamento quanto à proporção do aproveitamento, pela teoria tópica de Viehweg, da influência do pensamento de Leibniz, em seu estudo sobre a arte combinatória. A título ilativo, é possível anotar que, em perspectiva fria, Viehweg rechaça, em essência, os esforços dedicados por Leibniz e expõe que os equívocos de sua proposição estariam presentes já nas premissas de que partira: para o autor responsável pelo reacendimento da tópica no direito, não se há conceber qualquer oportunidade de comunicação entre a Jurisprudência e a operação de métodos dirigidos à aplicação do direito. Em geral, as referências feitas a Leibniz na obra Tópica e Jurisprudência ocorrem para criticar as tentativas de apor ferramentas lógicas para reunião de premissas, ainda que, no processo, seja conferida alguma liberdade inventiva. Ocorre que, como observado neste estudo, a tópica também influiu no desenvolvimento do pensamento combinatório de Leibniz - o caminho inverso àquele proposto por Viehweg -, com o intento de mitigar a homogeneidade sistêmica do método crítico em ascensão à época. Além disso, a arte combinatória foi um dos primeiros estudos do autor - realizado em sua juventude -, de modo que ignorar sua evolução teórica não se mostra prudente para qualquer empresa de aproveitamento adequado de seu raciocínio. Na obra Novos Ensaios sobre o Entendimento Humano dedicada a propor uma teoria do conhecimento -, por exemplo, Leibniz indica que não apenas a matemática poderia ser contemplada pelo raciocínio demonstrativo e que a lógica, se bem operacionalizada, não descarta a atividade criacional.

Com efeito, apesar de o raciocínio derivado de premissas providas de certa medida de probabilidade sujeitar a ocorrência de comprovações - não de demonstrações no sentido estrito do termo -, quanto mais próxima esteja a forma aplicada no raciocínio à daquele padrão lógico-matemático típico das demonstrações apriorísticas, maiores a segurança e a força passíveis de serem obtidas de suas inferências. Aliás, se é verdade que os modos de pensar sistêmicos ocasionam indesejada preterição dos problemas e merecem ser evitados, há que se observar que o projeto de Leibniz é 
pacificador, porquanto atribua aos modelos matemáticos função indispensável para que se possa manter a estratégia tópico-retórica sem desprezar a necessidade de garantir ao conjunto relativa estabilidade: o aproveitamento isolado de pontos de vista socialmente aceitos - longe de limitações de ordem sistemática e à revelia de qualquer procedimento lógico, como ansiado por Viehweg - não encerra condições pragmáticas de aplicação, sobretudo no contexto de elevado grau de especialidade e enraizamento das prescrições genéricas de condutas juridicamente aceitas e reprováveis, nos tempos atuais.

Ainda que fórmulas normativas traduzidas em símbolos e implantadas em notações matemáticas não sejam, concretamente, desejáveis e convenientes - mormente em função das restrições linguísticas, como pertinentemente experimentado por Leibniz e referido por Viehweg -, a articulação entre a ars inveniendi e a ars combinatória elevada pelo autor em sua juventude tem, a despeito de suas reconhecidas limitações práticas, razão de ser: proporciona a recompilação de termos em preceitos simples com vistas a uma avaliação mais adequada dos elementos de ordem fática - e permite o estabelecimento dos catálogos de tópicos que podem ser manejados no processo argumentativo, com vistas a garantir certa estabilidade ao intercâmbio articulado de pontos de partida. Além disso, oferece oportunidades dialógicas variáveis a todas as partes interessadas - conforme as combinações de elementos adotadas por elas para a defesa dos respectivos topoi - e valoriza o caráter interpretativo daquelas inferências para fornecer ao decisor, observado o dever de fundamentação igualmente dialogada do posicionamento adotado, o iter percorrido para achamento da inferência conclusiva solucionadora da questão posta - a saber: a demonstração do conjunto de combinações obtido para eleição daquela resposta tida como mais razoável - e, portanto, mais adequada, ante as particularidades do caso concreto -, com vistas ao alcance, em caráter conclusivo, mas permanentemente sujeito a questionamentos, da solução demandada pelo problema apresentado.

\section{REFERÊNCIAS}

ADEODATO, João Maurício. Retórica analítica como metódica jurídica. In: Argumenta. Jacarezinho: UENP, n 18, p. 11-29, 2013.

ALMEIDA, Juvencio. Theodor Viehweg: Jurisprudência, pensamento problemático e o retorno à tópica jurídica. In: Revista Direito e Liberdade. Natal: ESMARN, v. 14, nº 2, p. 123-142, 2012.

BONAVIDES, Paulo. Curso de direito constitucional. São Paulo: Malheiros, 2004.

BONNEAU, Cristiano. Fundamentos para uma ética em Leibniz. Tese apresentada ao Programa de Pós-Graduação em Filosofia, do Departamento de Filosofia da Faculdade de Filosofia, Letras e Ciências Humanas da Universidade de São Paulo, para a obtenção do título de Doutor em Filosofia. São Paulo: Universidade de São Paulo, 2015.

CHARLES, Mary Sol de Mora. Leibniz y los múltiples "usos" de su arte combinatoria. Aspectos matemáticos. In: COBO, Sonia de Paz. Historia de la probabilidad y la estadística. Asociación de Historiadores de Estadística y Probabilidad de España. Las Rozas de Madrid: Delta Publicaciones, 2014.

COELHO, Fábio Ulhoa. Prefácio à edição brasileira. In: PERELMAN, Chaïm; OLBRECHTSTYTECA, Lucie. Tratado da Argumentação: A Nova Retórica. $2^{\mathrm{a}}$ ed. São Paulo: Martins Fontes, 2005.

FRAZON, Carmen Rosane Pinto; BRITO, Arlete de Jesus. Um estudo sobre Leibniz e a criação de um alfabeto do pensamento humano. Jornada de Avaliação Continuada do Programa de Pós-Graduação em Educação Matemática. Rio Claro: UNESP: Universidade Estadual 
Paulista. Departamento de Matemática, 2013.

HART, Herbert. O Conceito de Direito. $5^{\text {a }}$ ed. Lisboa: Fundação Calouste Gulbenkian, 2007.

KANT, Immanuel. Crítica da razão pura. Lisboa: Fundação Calouste Gulbenkian, 2001.

LEIBNIZ, Gottfried Wilhelm. Philosophical Papers and Letters. v. 1. Chicago: The University of Chicago, 2011.

76 LEIBNIZ, Gottfried Wilhelm. Novos Ensaios sobre o Entendimento Humano. 5 a ed. São Paulo: Nova Cultural, 1992.

LEITE, George Salomão. Interpretação Constitucional e Tópica Jurídica. São Paulo: Editora Juarez de Oliveira, 2002.

LIMA, Newton de Oliveira. O estado de direito em Kant e Kelsen. Belo Horizonte: Editora D’Plácido, 2017.

LIMA, Newton de Oliveira. A teoria filosófica do direito de Hans Kelsen e seus contornos de legitimidade. In: Aufklärung: Revista de Filosofia. v. 3, nº 2. João Pessoa: Universidade Federal da Paraíba, 2016.

MENDONÇA, Paulo Roberto Soares. A Tópica e o Supremo Tribunal Federal. Rio de Janeiro: Renovar, 2003.

MOREIRA, Vivianne de Castilho. Leibniz e o Problema da Linguagem. Conferência de Encerramento. Colóquio Leibniz no Nordeste. João Pessoa: Universidade Federal da Paraíba, 2017.

PERELMAN, Chaïm; OLBRECHTS-TYTECA, Lucie. Tratado da Argumentação: A Nova Retórica. $2^{\mathrm{a}}$ ed. São Paulo: Martins Fontes, 2005.

RATEAU, Paul. Leibniz et Le meilleur des mondes possibles. Trad.: BONNEAU, Cristiano; MOREIRA, Viviane de Castilho. Conferência de abertura. Colóquio Leibniz no Nordeste. João Pessoa: Universidade Federal da Paraíba, 2017.

ROESLER, Cláudia Rosane. Saber Jurídico, Retórica e Ciência: Uma análise da obra de Theodor Viehweg. São Paulo: Universidade de São Paulo. Faculdade de Direito. Tese apresentada como requisito à obtenção do título de Doutor em Direito, na Área de Concentração de Filosofia e Teoria Geral do Direito, 2002.

RUSSELL, Bertrand. A Filosofia de Leibniz: uma exposição crítica. São Paulo: Editora Nacional, 1968.

VIEHWEG, Theodor. Tópica e Jurisprudência. Brasília: Universidade de Brasília, 1979.

WIEACKER, Franz. História do Direito Privado Moderno. $2^{\mathrm{a}}$ ed. Lisboa: Fundação Calouste Gulbenkian, 1967. 